Neuroepidemiology 2011;36:121-122

DOI: $\underline{10.1159 / 000324174}$

\section{Stress and Multiple Sclerosis: What's New?}

Julián Benito-León ${ }^{\mathrm{a}-\mathrm{c}}$

a Department of Neurology, University Hospital '12 de Octubre', b Centro de Investigación Biomédica en Red sobre Enfermedades Neurodegenerativas, and ${ }^{\mathrm{C}}$ Department of Medicine, Faculty of Medicine, Complutense University, Madrid, Spain

A man who suffers before it is necessary, suffers more than is necessary.

Lucius Annaeus Seneca

Multiple sclerosis (MS) is one of the most common chronic inflammatory and neurodegenerative diseases, placing a substantial burden on patients, their families and carers, as well as on society as a whole $[1,2]$. MS can severely affect the health-related quality of life (HRQOL) of both patients and their caregivers and, as the disease progresses, HRQOL deteriorates [3-11].

In MS, symptom expression is likely determined to a similar extent by genetic and environmental factors. Although an increasing body of evidence suggests that this disease is mediated by an autoimmune reaction among susceptible people to a widespread pathogen (Epstein-Barr virus?, Candida species?) [12, 13] that is ubiquitous in the developed world, none of the current hypotheses on the etiology of MS are completely convincing [14].

Many of the chronic diseases that plague modern society are preceded by unhealthy lifestyle choices or events, often taking many years to develop and mature to a stage where symptoms and signs become manifest. Of the many lifestyle events that affect human beings, none is more common than stress and stress-related conditions $[15,16]$. Stress has been defined as an emotional experience associated with nervousness, tension, and strain [15, 16]. Although cardiovascular disease is by far the most commonly studied health condition that has been linked to stress [15], since the first description of MS by Jean-Martin Charcot, it has been believed that that disease has also been triggered by stress.

The central nervous system and the immune system are two extremely complex and highly adaptive systems. In healthy individuals, the communication between these two systems is finely balanced. In MS, an excess of inflammatory processes seems to be a hallmark and there is growing evidence that a crucial pathogenic factor is a disturbed communication between the central nervous system and the immune system [17]. Bidirectional relationships between the immune system, central nervous system, and psychological processes probably exist in MS because stress can affect MS [18], and MS is associated with an increased risk of psychological difficulty $[3,19]$.

Furthermore, the hypothalamic-pituitary-adrenal axis, sympathetic-adrenomedullary system, proinflammatory cytokines, substance $\mathrm{P}$, and mast cells are impaired in MS [20-23]. These also respond to stress, and they have been implicated in psychological problems in otherwise healthy individuals [24]. However, further research is required in order to understand the links between these impaired systems and psychological function in MS. The recent advances of psychoneuroimmunology, the discipline which focuses on the mechanisms underlying crosstalk between the brain and the immune system, might offer some insights into the pathogenesis of MS [17].

In the present issue of Neuroepidemiology, Artemiadis et al. [18] review the literature pertaining to the role of psychological stress in MS onset and relapses. They searched MEDLINE with the terms 'stress' and 'multiple sclerosis', selecting English language articles published between January 1980 and November 2010. The authors included only observational longitudinal studies [18].

Seventeen publications were analyzed [18], 5 for MS onset (1 cohort and 4 case-control studies) and 12 for MS relapses ( 9 cohorts and 3 case-control studies). The authors discussed a number of limitations of these studies [18] and the quality of the studies varied significantly. Studies failed to control adequately for various triggering and psychosocial factors for the stress-MS relationship. Future studies designed to clarify the link between stress or a significant stressful life event and the development of MS should adjust for possible confounders such as lifestyle factors or physical trauma, infections, family history, or occupational exposures or other factors that might also contribute to MS risk and which may have been different between the studied populations. Finally, problems with selection and blindness were identified in most case-control studies. As noted by the authors, all studies, except for 2, indicated a link between stress and MS [18].

While this study summarizes the existing literature on the possible link between stress and MS, it does not clarify all issues. Rather than establishing a 'causal' relationship between stress and MS, the investigators documented that, due to marked stress measurement heterogeneity, no secure conclusions could be drawn. The investigators noted that future studies should incorporate a multidisciplinary approach of stress measurement and radiological criteria for MS and they recommend testing the effect of early life stress and stress management techniques in the clinical course of the disease.

It appears likely that in the near future, mental stress testing may become part of the clinical armamentarium of the practicing physician to identify patients at risk for MS or at risk of suffering from relapses. If indeed those with mental stress are at increased risk of developing MS or relapses, it is incumbent upon us to work

\section{KARGER}

(c) 2011 S. Karger AG, Basel

Fax +41613061234 E-Mail karger@karger.ch www.karger.com
Accessible online at: www.karger.com/ned 
in a multidisciplinary fashion to establish a suitable therapeutic approach.

In conclusion, when our MS patients say that stress worsens their disease, they may be correct. Although the study of stress is fraught with problems, there may be both immune mechanisms (that is, psychoneuroimmunology processes) and nonimmune mechanisms that are responsible for increased disease activity and/or symptom expression during periods of stress. The research by Artemiadis et al. [18] should stimulate more research on how stress may impact the biological processes that lead to MS.

\section{Acknowledgement}

Dr. Benito-León is supported by NIH R01 NS039422 from the National Institutes of Health, Bethesda, Md., USA.

\section{References}

1 Compston A, Coles B: Multiple sclerosis. Lancet 2008;372:1502-1517.

-2 Benito-León J, Martin E, Vela L, Villar ME, Felgueroso B, Marrero C, Guerrero A, Ruiz-Galiana J: Multiple sclerosis in Móstoles, central Spain. Acta Neurolo Scand 1998;98:238-242.

3 Benito-León J, Morales JM, Rivera-Navarro J: Health-related quality o life and its relationship to cognitive and emotional functioning in multiple sclerosis patients. Eur J Neurol 2002;9:497-502.

4 Benito-León J, Martínez-Martín P: Health-related quality of life in multiple sclerosis. Neurologia 2003;18:210-217.

5 Benito-León J, Morales JM, Rivera-Navarro J, Mitchell A: A review about the impact of multiple sclerosis on health-related quality of life. Disabil Rehabil 2003;25:1291-1303.

-6 Morales-González JM, Benito-León J, Rivera-Navarro J, Mitchell AJ, GEDMA Study Group: A systematic approach to analyse health-related quality of life in Multiple Sclerosis: the GEDMA study. Mult Scler 2004 10:47-54.

7 Mitchell AJ, Benito-León J, González JM, Rivera-Navarro J: Quality of life and its assessment in multiple sclerosis: integrating physical and psychological components of wellbeing. Lancet Neurol 2005;4:556566.

8 Rivera-Navarro J, Morales JM, Benito-León J: Informal caregiving in multiple sclerosis patients: data from the Madrid demyelinating disease group study. Disabil Rehabil 2003;25:1057-1064.

-9 Rivera-Navarro J, Morales-González JM, Benito-León J, Mitchell AJ The social and familial dimensions: experiences of caregivers and people with Multiple Sclerosis. The Gedma Study. Rev Neurol 2008;47: 281-285.

10 Rivera-Navarro J, Benito-León J, Oreja-Guevara C, Pardo J, Dib WB, Orts E, Belló M, Caregiver Quality of Life in Multiple Sclerosis (CAREQOL-MS) Study Group: Burden and health-related quality of life of Spanish caregivers of persons with multiple sclerosis. Mult Scler 2009;15:1347-1355.
11 Benito-León J, Rivera-Navarro J, Guerrero AL, de Las Heras V, Balseiro J, Rodríguez E, Belló M, Martínez-Martín P, on behalf of the caregiver quality of life in multiple sclerosis (CAREQOL-MS) Study Group: The CAREQOL-MS was a useful instrument to measure caregiver quality of life in multiple sclerosis. J Clin Epidemiol 2010, E-pub ahead of print.

12 Kakalacheva K, Comabella M: Epstein-Barr virus and multiple sclerosis: causation or association? Future Microbiol 2010;5:1617-1619.

- 13 Benito-León J, Pisa D, Alonso R, Calleja P, Díaz-Sánchez M, Carrasco L: Association between multiple sclerosis and Candida species: evidence from a case-control study. Eur J Clin Microbiol Infect Dis 2010; 29:1139-1145.

14 Benito-León J, Bermejo-Pareja F: Is the epidemiology of multiple sclerosis changing? Rev Neurol 2010;51:385-386.

15 Kalia M: Assessing the economic impact of stress-the modern day hidden epidemic. Metabolism 2002;51(6 suppl 1):49-53.

- 16 Cooke RA, Rousseau DM: Stress and strain from family roles and workrole expectations. J Appl Psychol 1984;69:252-260.

17 Kern S, Ziemssen T: Brain-immune communication psychoneuroimmunology of multiple sclerosis. Mult Scler 2008;14:6-21.

18 Artemiadis AK, Anagnostouli MC, Alexopoulos EC: Stress as a risk factor for multiple sclerosis onset or relapse: a systematic review. Neuroepidemiology 2011;36:109-120.

19 Olazarán J, Cruz I, Benito-León J, Morales JM, Duque P, Rivera-Navarro J: Cognitive dysfunction in multiple sclerosis: methods and prevalence from the GEDMA Study. Eur Neurol 2009;61:87-93.

20 Ysrraelit MC, Gaitán MI, Lopez AS, Correale J: Impaired hypothalamic-pituitary-adrenal axis activity in patients with multiple sclerosis. Neurology 2008;71:1948-1954.

21 Matusevicius D, Navikas V, Söderström M, Xiao BG, Haglund M, Fredrikson S, Link H: Multiple sclerosis: the proinflammatory cytokines lymphotoxin-alpha and tumour necrosis factor-alpha are upregulated in cerebrospinal fluid mononuclear cells. J Neuroimmunol 1996; 66:115-123.

22 Kostyk SK, Kowall NW, Hauser SL: Substance P immunoreactive astrocytes are present in multiple sclerosis plaques. Brain Res 1989;504: 284-288.

23 Theoharides TC, Kempuraj D, Kourelis T, Manola A: Human mast cells stimulate activated T cells: implications for multiple sclerosis. Ann NY Acad Sci 2008;1144:74-82.

24 Alexander N, Kuepper Y, Schmitz A, Osinsky R, Kozyra E, Hennig J: Gene-environment interactions predict cortisol responses after acute stress: implications for the etiology of depression. Psychoneuroendocrinology 2009;34:1294-1303.

Dr. Julián Benito-León

Department of Neurology, University Hospital '12 de Octubre'

Av. de Córdoba, s/n

ES-28041 Madrid (Spain)

Tel. +34913908600, E-Mail jbenitol@meditex.es 